\title{
Current Research Trends of SLA and Challenges and Strategies for Native Chinese English-learners
}

\author{
Ming Cao \\ Humanities and International Education College, Xi’an Peihua University, 888 Changning Street, Xi'an, \\ China \\ 2745359275@qq.com
}

Keywords: Cognitive oriented perspective, social oriented perspective, Chinese English-learners, challenges and strategies

\begin{abstract}
Current research of second language Acquisition (SLA) has several main trends: cognitive oriented perspective, social oriented perspective, and holistic perspective. Under these perspectives, many theories have been used to explain the process of SLA such as, primary theory, the theory of affordances, and sociocognitive approach. These provided solid foundations towards understanding second language acquisition. Based on the perspectives of SLA, this paper aims to re-explore the challenges and strategies of native Chinese English-learners. This group of people may have more challenges to learn English as a second/foreign language compared with other ethnic groups whose mother tongues are alphabetic based languages. It could be related to thinking differences, language distance, as well as effective teaching methods. As a result, teaching under holistic perspective may be a practical method to enhance Chinese English-learners.
\end{abstract}

\section{Introduction}

Among different languages, English is one of the most popular languages widely used and studied in the world. Despite of the various purpose of English learning, people from different countries have different challenges and strategies. For native Chinese speakers, there are many successful examples to acquire English proficiency. For example, Tubergen and Kalmijn (2009) reported that Chinese immigrants in the US arrived with around 35\% people speaking English well, and after 20 years in the US, extra 25\% Chinese immigrants spoke English well. Others, however, have reported that it seemed to be challenging for Chinese English-learners to acquire English proficiency. These people perhaps had more difficulties learning English because of their learning abilities, their ages, and their cultural background (D. Zhang, 2010).

\section{Current Research Trends}

Current research on SLA has two dominant research dimensions: cognitive oriented approach and social oriented approach (Firth \& Wagner, 1997). Before the social and contextual orientation was introduced in 1996 by Firth and Wagner, cognitive research method dominated SLA research for 30 years, although many researchers brought social related indicators in the cognitive oriented research. In the past 15 years, debates and issues focused on the dispute between cognitive and sociocultural perspectives in SLA. In a holistic point of view, whether the balance between cognitive and social oriented approaches has been built up, both perspectives are valuable to explore the challenges and strategies for second language learning/foreign language learning (SLL/FLL).

\subsection{Cognitive Oriented Perspective}

Many researchers contributed to the development of the cognitive oriented research field. Fries (1954), for example, systemically discussed the features of adult English learning including the 
sounds, the structure, the words, the contextual orientation, and so on. Chomsky (1959) disagreed with the perspective of behaviourism by Skinner and presented his own views of language learning in the ways of improving the frame of modern linguistics, psychology, and philosophy. Up to the 1990s, cognitive oriented approaches had many valuable results making teachers and learners understand how the second language (L2) has been processed and adopted. The perspective of Kasper (1997) clearly told us that cognitive processing is the main method for the brain to learn new things. Along with the tremendous growth of neuroscience over the last 15 years, many new findings strongly support the cognitive processing perspective of SLA. For example, event-related brain potentials (ERP) showed that late English learners did not rely on left hemisphere systems for grammatical processing but used both hemispheres to finish the processing (Weber-Fox \& Neville, 1996). This evidence shows that English can be acquired by processing in different ways in our brains.

\subsubsection{Priming theory}

The concept of priming has been well attested for over a hundred years but only applied in second language research in recent years (Benati, 2009). The definition of priming is described as "the phenomenon that prior exposure to something influences subsequent responses to the same or related things" (Benati, 2009, p. 10). Language learning has this property that previous linguistic features influence the subsequent language learning. According to Benati (2009), for example, the previous features of language influence the current language learning in reaction time, amount of use, accuracy, preference, and opinion, and so forth. There are positive effects, which facilitate second language learning, and negative effects, which inhibit second language learning.

Cross-language priming experiments have typically shown that words in different languages primed each other (Jiang, 1999; Keatley, Spinks, Gelger, 1994). Keatley et al. (1994) found that priming occurred only when the prime was in their first language and it showed asymmetrical features by whatever among alphabet languages or between alphabet and nonalphabet languages. According to Jiang (1999), priming from Chinese to English was stronger than from English to Chinese by native Chinese subjects. The reaction time was shorter when the subjects recognized or translated an English word to a Chinese word than a Chinese word to an English word. Structural priming or syntactic priming was discovered more than 20 years and there are more than 100 studies that have used this method (Pickering \& Ferreira, 2008). Cultural priming is also used to research individuals' self-construal and attendant memory strategies.

\subsubsection{The Theory of Affordances}

According to perceptual psychologist James J. Gibson (1977, 1979), affordance dealt with the mutual relationships between the organism and its environment in the perception area; it is the perceived opportunities that the environment provided or afforded; it is "a specific combination of the properties of [the environment's] substance and its surfaces taken with reference to the animal" (as cited in Angelis \& Dewaele, 2011, p.1). Heft (2001) provided an elaboration of this term as "an affordance is the perceived functional significance of an object, event, or place for an individual. For example, a firm, obstacle-free ground surface is perceivable as a surface on which one can walk” (as cited in Singleton \& Aronin, 2007, p. 84).

Based on these elaborations, Angelis and Dewaele (2011) found that language learners have certain potential affordances when they deal with language resources at their language learning and using environment. Multilingual language learners/users have more potential affordances available to them than other language users. Segalowitz (2001) believed that learners may be different in flexibility and fluency when dealing with a specific language situation, but their second language performance may be sensitive to environmental affordance, such as the ability to adjust the linguistic and nonlinguistic context of changing. When talking about language distance, Angelis and Dewaele explained that "awareness and readiness to use the affordances offered by the cognate vocabulary depends, first of all, on the perceived psychotypological distance between L1 and L2" (p. 5). Although there are not many research studies based on affordance for language acquisition, it provides inspiration for us to understand second or more language acquisition. 


\subsection{Social Oriented Perspective}

According to Firth and Wagner (1997), the ultimate goal of social oriented perspective is to argue for a reconceptualization of SLA as a more theoretically and methodologically balanced enterprise that endeavours to attend to, explicate, and explore, in more equal measures and, where possible, in integrated ways, both the social and cognitive dimensions of S/FL use and acquisition.

This perspective was built upon critically theoretical assumptions and methodological practices and to challenge the cognitive research authority. In the early $20^{\text {th }}$ century, Vygotsky had already asserted that all fundamental cognitive activities have social foundations; he posited that learning and development occurred on social and psychological dimensions; the "zone of proximal development (ZPD)" is the central part of his theory (Dimitriadis \& Kamberelis, 2006). Recently, SLA researches relating to sociocultural background are more and more popular. Lybeck (2002) researched nine American women who studied Norwegian and found that the success of L2 is the strongest linguistic marker of a learner's cultural identification. Tarone (2007) had an incisive analysis for building up a socioliguistic model of SLA. She stated that the model and the theory "view the learner as a social being whose cognitive processing of the L2 is affected by social interactions and social relationships with others, including those others who provide L2 input and corrective feedback” (p. 840).

\subsection{Sociocognitive Approach}

Nowadays, A notion of a sociocognitive approach gradually appeared. According to Atkinson (2002), the sociocognitive perspective is that one side "is embedded in cognitive space, the other end is just as strongly embedded in social space” (p. 538). There are several main points involved in this term explaining by Atkinson. First, the sociocognitive approach to SLA is that "teaching is valuable, and learning and teaching go hand-in-hand” (p. 538). It embeds the relationship of equity, cooperation, and interaction. It also emphasizes that peers or other social members can be teachers, but it depends on the situation. Second, language is intimately related to the outside world. Language information is not only transferred from brain to brain. It has many connections with other fields, such as: culture, schooling, identity, ideology, discourse, social ecology, embodied action-taking, and so on. Third, since ethnographic research method will have a central place in this area, qualitative research approaches in the natural environment are mainly adopted. Fourth, these approaches "will provide a means by which second language learners can be seen as real people, doing something they naturally do-not as mere research subjects, or mere students, or mere sites for language acquisition” (p. 539). Here are handful researches. Gee (2001) argued that reading as situated language happens within a broad viewpoint that integrates work on cognition, language, social interaction, society, and culture. Atkinson et al. (2007) used qualitative methods in their SLA research on a junior high school student in Japan and found that the student and her tutor focused on the coordinated activities in their sociocognitively constructed world. Dyson (2010) presented that there is a relationship between SLA and education and we need to create a synergy between sociocognitive pedagogies and social and cognitive constructs. Churchill, Nishino, Okada, and Atkinson (2010) also analysed the tutor-learner interaction and suggested that symbiotic gesture is one example of humanly improvised resources guiding ecosocial alignment and participation in SLA. More effective studies need to be developed on this perspective.

\subsection{Strategy Researches}

Strategy research is one of the main parts in the SLA research field. In ancient Greece, strategy involved a general's plan to win a war (Oxford, 2000, as cited in Oxford, 2003b). Chamot (2004) explained that learning strategies are "the conscious thoughts and actions that learners take in order to achieve a learning goal” (p. 14). Cohen (1998) defined L2 strategies as "any strategies related to the second language learning including strategies for learning or using the L2" (as cited in Oxford, 2003b, p. 274). Scarcella and Oxford (1992) described L2 learning strategies as "specific actions, behaviours, steps, techniques [or thoughts] - such as seeking out conversation partners, or giving oneself encouragement to tackle a difficult language task -used by students to enhance their own 
learning" (as cited in Oxford, 2003b, p. 274). Oxford (2003a) also stated that "learning strategies can be classified into six groups: cognitive, metacognitive, memory-related, compensatory, affective, and social” (p. 2). Learners who have good strategies should understand their goals of learning and know themselves and task requirements very well.

Strategy research can be classified by learners' personal characteristics, such as age, gender, motivation, and so on, and teaching strategies as well. Nisbet, Tindall, and Arroyo (2005) investigated the relationship between language strategy preference and English proficiency among Chinese university students. They found that although there are no significant differences between males and females on the measures, learner autonomy, in diverse cultural settings, needs to be further examined. Another research by Dretzke and Jordan (2010) showed that the motivations between Asian students and White students are apparently different when learning Chinese as a second language, so the strategies they used or were expected to use were different.

\subsubsection{Thinking Differences and SLA}

There are various researches regarding with thinking differences while learning English. Nisbett (2003) pointed out that it was the living conditions including geographical features and social organizations between Ancient Greece and China that caused the difference. From the cognitive processing view, SLA not only transits the language itself, but also passes one geometrical system of reference to another. Pavlenko (2011) clearly analysed it is apparently true that learners' thinking are still kept in L1when they have already acquired L2. This phenomenon is also explained by Affordance theory that "how the thing could possibly be used" (Norman, 2002, as cited in Singleton \& Aronin, 2007, p. 84). It showed that our brains just chose the most effective way to use the resources that are constructed in our minds. Nevertheless, this easiest way of working does not always receive expected results when Chinese learners learn English.

A famous research by Boroditsky (2001) investigated different groups of Mandarin speakers and English speakers. He found that Mandarin speakers preferred to describe time as vertical, but English were likely to talk time as if it were horizontal. But then, after English group received training, they could change their thinking conversely despite that they did not indulge in the real culture environment. Coming back to SLA, although Boroditsky only trained English group by changing their way of thinking to the Chinese way and did not train Mandarin speakers to think like English speakers, it is obvious that thinking habits can be changed if there is enough time to practice. Therefore, it apparently provides us a great deal of enlightenment for English learning.

\subsubsection{Language Distance and SLA}

There are different explanations for the term of language distance. Elder and Davies (1998) described language distance as "the relative degree of similarity between two languages" (p. 1).Language distance has a cross-linguistic influence; the influence is stronger at early stage, and when the learner has proficiency of L2, the influence of L1 is lower (Benati, 2009; Ringbom, 1987, as cited in Elder \& Davies, 1998). There is some evidence to support cross-linguistic influences. For example, Tan et al. (2003) found that Chinese readers were less capable of processing English because they applied their L1 system to L2 reading. Tokuhama-Espinosa (2008) emphasized that the quality of mother tongue had a strong influence on the second or multilanguage acquisition.

In addition, the differences from cultural and social backgrounds make the linguistic distance even greater. Compared with Chinese language, English has many phrasal verbs which can be understood only in contextual background. Learners need to concentrate more on local cultures, situations, and habits. For example, the phrase "hit me up" is not beating someone but "keep in touch"; "emergency policeman" is not a temporary police worker but a volunteer who works between policemen and civilians helping people understand the work of police, and so on.

\subsubsection{About Teaching and Learning Methodologies}

Research shows that there is a strong relationship between learning strategies and English proficiency among English learners in South Africa (Nisbet et al., 2005), a small and moderate correlation in Korea (Park, 1997), and a minimal correlation in China (Nisbet et al., 2005). It seems 
that there are somewhat differences between Chinese English-learners and English-learners from other countries. Therefore, we have some implications. First, pay attention to the social background. As there are differences between China and Western countries in political, historical, geographical, linguistic, and cultural backgrounds, different methodologies should be used when teaching these learners. Students need to be active in class, having their own points of view, and they need to be ready to engage in discussion all the time. Second, cultural differences are another concern if Western-guided strategies are abruptly used. According to Mundy et al. (2008), in East Asia, Western education values interacted with Confucian traditions, under conditions of capitalist modernization and socialist construction. Although allowing different ideas, Confucian ideology is highly valued in the educational field. Modest behaviour, not showing off, and self-control are core values that Chinese people adhere to. All these cultural elements imprint in Chinese people's minds. Third, Antonio Gramsci had a notion that "every language contains elements of a conception of the world" (as cited in Giroux \& McLaren, 1986, p. 230). Knowledge is constructed in a specific way in Chinese students' minds. As a result, English teaching and learning are highly based on understanding the background information. Teachers and students should open their minds to reexamine their methods and to build up more effective ways of learning.

\section{Conclusion}

For Chinese English-learners, it is apparent that challenges and strategies not only lies on word choosing, but the thinking style, the language sensitivity, and the learning habit. Chinese Englishlearners obviously have more difficulties acquiring English language compared with other ethnic learners. To help Chinese English-learners, holistic perspective should be adopted, while keeping in mind that learning not only transfers information from brain to brain, but happens in the contextual setting. Learners should understand the meanings not only literally but under specific language environments as well. Teachers, on the other hand, should highly connect the practical meanings when they teach words, sentences, and paragraphs. A variety of student-centred methods should be taken into account such as, situational teaching and task-based teaching, through multi modal ways.

\section{Acknowledgement}

2016 Shaanxi Science of Education “Thirteen-Five”Project “An Empirical Study on Improving Autonomous Learning Ability of English Major Students Based on Theory of Multimodality", Project No. SGH16H225; 2017 Higher Education Science Project from Shaanxi Association of Higher Education "Research on Countermessures of Improving English Output competence of students in Application-Oriented University Based on Context of Globalization”, Project No.XGH17190

\section{References}

[1] Angelis, G. D. \& Dewaele, J. M. New trends in crosslinguistic influence andmultilingualism research. Toronto, Canada: Multilingual Matters, 2011.

[2] Atkinson, D. Toward a sociocognitive approach to second language acquisition. The Modern Language Journal, 2002, 86(4), 525-545.

[3] Atkinson, D., Nishino, T., Churchill, E., \& Okada, H. Alignment and interaction in a sociocognitive approach to second language acquisition. The Modern Language Journal, 2007, 91(2), 169-188.

[4] Boroditsky, L. Does language shape thought?: Mandarin and English speakers' conceptions of time. Cognitive Psychology, 2001, 43, 1-22.

[5] Chamot, A. U. Issues in language learning strategy research and teaching. Electronic Journal of Foreign Language Teaching, 2004, 1(1), 14-26. 
[6] Chomsky, N. A review of B. F. Skinner's verbal behavior. Language, 1959, 35 (1), 26-58.

[7] Dimitriadis, G., \& Kamberelis, G. Theory foreducation. New York, NY:Routledge, 2006.

[8] Dretzke, B. J., \& Jordan, K. Expanding secondary school Chinese language programs: A study of potential challenges. American Secondary Education, 2010, 38(2), 57-72.

[9] Dyson, B. On sociocognitive approaches to second language pedagogy. Australian Review of Applied Linguistics, 2010, 33(3), 251-262.

[10] Elder, C., \& Davies, A. Performance on ESL examinations: Is there a language distance effect? . Language and Education, 1998, 12(1), 1-17.

[11] Firth, A., \& Wagner, J. On discourse, communication, and (some) fundamental concepts in SLA research. The Modern Language Journal, 1997, 81(3), 285-300.

[12] Fries, C. C. Teaching and learning English as a foreign language. http://www.eric.ed.gov.proxy.library.brocku.ca/ERICWebPortal/search/detailmini.jsp_nfpb=true\&_ \&ERICExt

Search_SearchValue_0=ED071477\&ERICExtSearch_SearhType_0=no\&accno=ED071477, 1954.

[13] Gee, J. P. Reading as situated language: A sociocognitive perspective. Journal of Adolescent \& Adult Literacy. 2001, 44(8), 714-725.

[14] Giroux, H. A., \& McLaren, P. Teacher education and the politics of engagement: The case for democratic schooling. Harvard Educational Review. 1986, 56(3), 213-238.

[15] Jiang, N. Testing processing explanations for the asymmetry in masked cross-language priming. Bilingualism: Language and Cognition, 1999, 2(1), 59-75.

[16] Kasper, G. “A” stands for acquisition: A response to Firth and Wagner. The Modern Language Journal, 1997, 81(3), 307-312.

[17] Keatley, C. W., Spinks, J. A., \& Gelder, B. D. Asymmetrical cross-language priming Effects. Memory \& Cognition, 1994, 22(1), 70-84.

[18] Lybeck, K. Cultural identification and second language pronunciation of Americans in Norway. The Modern Language Journal, 2002, 86(2), 174-191.

[19] Mundy, K., Bickmore, K., Hayhoe, R., Madden, M., \& Madjidi, K. Philosophy and comparative education: What can we learn from East Asia? In R. Hayhoe (Ed.), Comparative and international education (pp. 23-48). Toronto, Canada: Canadian Scholars’ Press, 2008.

[20] Nisbet, D. L., Tindall, E. R., \& Arroyo, A. A. Language learning strategies and English proficiency of Chinese university students. Foreign Language Annals, 2005, 18(1), 100-107.

[21] Nisbett, R. E. The geography of thought. New York, NY: Free Press, 2003.

[22] Oxford, R. L. Language learning styles and strategies: Concepts and relationships. International Review of Applied Linguistics in Language Teaching, 2003b, 41(4), 271-278.

[23] Park, G. Language learning strategies and English proficiency in Korean university Students. Foreign Language Annals, 1997, 30(2), 211-221.

[24] Pavlenko, A. Thinking and speaking in two languages. Bristol, UK: Multilingual Matters, 2011.

[25] Pickering, M. J., \& Ferreira, V. S. Structural priming: A critical review. Psychological Bulletin, 2008, (3). 427-459.

[26] Segalowitz, N. On the evolving connections between psychology and linguistics. Annual Review of Applied Linguistics, 2001, 21(3), 3-22.

[27] Singleton, D., \& Aronin L. Multiple language learning in the light of the theory of Affordances. Innovation in Language Learning and Teaching, 2007, 1(1), 83-96. 
[28] Tarone, E. Sociolinguistic approaches to second language acquisition research - 1997-2007. The Modern Language Journal, 91(Focus issue), 2007, 837-848.

[29] Tokuhama-Espinosa, T. Living languages: Multilingualism across the lifespan. Westport, CT: Praeger, 2008.

[30] Tubergen, F. V., \& Kalmijn, M. A dynamic approach to the determinants of immigrants' language proficiency: The United States, 1980-2000. International Migration Review, 2009, 43(3), 519-543.

[31] Weber-Fox, C. M., \& Neville, H. J. Maturational constraints on functional specialization for language processing: ERP and behavioural evidence in bilingual speakers. Journal of Cognitive Neuroscience, 1996, 8, 231-256.

[32] Zhang, D. Language maintenance and language shift among Chinese immigrant parents and their second-generation children in the U.S. Bilingual Research Journal, 2010, 33, 42-60. 